\title{
Improving BPMN2 Business Process Model to SBVR Business Vocabulary and Business Rules Transformation with BPMN2 Event Naming Patterns
}

\author{
Eglè Mickevičiūtė, Lina Nemuraitė, Rimantas Butleris \\ Kaunas University of Technology, Department of Information Systems, \\ Studentu st. 50, LT-51368 Kaunas, Lithuania, \\ Kaunas University of Technology, Centre of Information Systems Design Technologies, \\ K. Barsausko st. 59, LT-51423 Kaunas, Lithuania, \\ e-mail:egle.mickeviciute@ktu.lt,lina.nemuraite@ktu.lt,rimantas.butleris@ktu.lt \\ cross ref http://dx.doi.org/10.5755/j01.itc.45.4.14965
}

\begin{abstract}
The goal of the paper is to define naming patterns for BPMN2 events in order to process them differently to obtain the most complete and semantically correct SBVR business vocabulary and business rules as possible. The paper presents BPMN2 events and their representation in SBVR as a separate part of BPMN2 business process models transformation to SBVR business vocabulary and rules. As different BPMN2 events present different process behavior, they should be analyzed and processed separately to have full and comprehensive set of SBVR business vocabulary and business rules as they present terms, restrictions and business logic in organizations. Running example is presented for a better understanding. Overall approach recently has become available in UML CASE tool MagicDraw after implementing SBVR plugin based on UML profile for SBVR. The approach was implemented using QVT transformation language.
\end{abstract}

Keywords: BPMN2; SBVR; representation; transformation; BPMN2 events.

\section{Introduction}

Business process modelling has become an inherent part of IS development, which usually starts from an agreement on a shared vocabulary among all stakeholders from the business analysts to technical developers and business managers. To involve all stakeholders in this process is vital in order to validate collected requirements [3], [9] in a stage where necessary changes can be easily applied. Business process modelling is one of the main steps in developing information systems, but the first step is to define business vocabulary and business rules. Unfortunately, there is a gap between those two different modelling approaches as business process models are usually presented using graphical notation while business vocabulary and business rules are presented using structured natural language.

A large number of graphical process modelling languages have been developed to help organizations with documentation of their business processes. BPMN2, a new version of BPMN (Business Process Model and Notation) [20], became a standard for graphic process modelling because it has attracted a lot of interest as no other notation for business process modelling had such an uptake in such a short time [4]. As the survey [4] showed, one of the highlight deficits of BPMN is related with the business rules as an extension of BPMN. There is a need to combine business process modelling and business vocabulary and business rules modelling approaches as they kept complementary each other [11]. SBVR (Semantics of Business Vocabulary and Rules) [22], [23] is an OMG (Object Management Group) standard for business vocabulary and business rules modelling.

As BPMN2 is presented using graphical notation and SBVR is presented in natural structured language, the problem occurs with integration and transformation. BPMN2 has a large set of graphical elements and SBVR has less elements for vocabulary and rules representation. The largest group of BPMN2 elements is the group of events. There are 5 types of BPMN2 events and each of them has their own types. In order to get correct SBVR business vocabulary and business rules from BPMN2 business process model, BPMN2 events should be named in correct form. This paper presents naming patterns for BPMN2 events in order to get correct SBVR business vocabulary and business rules after transformation. 
The rest of the paper is organized as follows. In Section 2, an overview of related works is presented. Section 3 presents BPMN2 event types. Section 4 describes the classification of BPMN2 events and their naming patterns in order to represent them in SBVR. Running example is also presented in Section 4. Section 5 considers experimental evaluation of transformation results. Finally, conclusions and future works are summarized and revealed in Section 6. The acknowledgement finalizes the paper.

\section{Related Works}

Business process models are used to document and continuously improve business operations in organizations. In order to have full documentation of a business process, business vocabulary and business rules must be identified. As business process modelling defines models in procedural way using notations, business rules modelling defines models using structured language in declarative way. These two aspects of the process should be modelled separately, however, they should be integrated in order to manage business processes in practice. The comprehensive integration or mutual transformation between business process and business rules models are two inseparable approaches [6]. As the literature shows, this capability attracts more and more attention. The need of business process models and business rules models combination was presented in [11].

The analysis of business process and business rules modelling languages (Petri Net, IDEF3, EPC, BPMN; SWRL, SRML, PRR, SBVR) [19] has shown that the best representation power of business processes with minimum overlapping is described by BPMN with SRML and BPMN with SBVR combinations. BPMN and SBVR were chosen for integrating and transforming business process and business rule models because SBVR is supported and updated continually while SRML specification has no further updates.

Several proposals for integrating business processes and business rules were made. The Gartner group report [13] has introduced seven scenarios of how processes and rules can be defined. Scenarios were critically reviewed and reduced to four key patterns of rule usage [12]. These scenarios were defined in theoretical matter with no information for the implementation.

Declarative business process modelling proposal was given in [27]. The main disadvantage of declarative approaches is that business process models are better understandable for business participants and computers when they are modelled in the procedural (graphical) way [18], [15], [16], [14]. Graphical business process modelling can be improved and accelerated using business rules templates [17], [30]. In a contrast, visual notations were introduced as the proposal for expressing business rules in a graphical notation via modelling methods of Ross [26] and Visual SBVR [24]. The main disadvantage of visual notations of business rules is that their graphical models are very large, hard to read and require a lot of elements for correct and full representation what makes this proposal hard and inconvenient to use as a user has to remember all the elements.

According to the previous analysis the suggested solution should be based on BPMN and SBVR metamodels [19]. There are no full mappings of BPMN and SBVR elements as current proposals are able to deal with a limited number of BPMN and SBVR constructs. Automated method to transform BPMN business process model to SBVR structured language was proposed by Malik et al. [29], [28]. A bottom-up approach to integrate business processes and business rules was presented by Cheng et al. [25]. The proposal to extend SBVR metamodel for representing business process vocabularies was presented [1], but as SBVR or BPMN metamodels are continually updated such an extension is not suitable. Also, supplementary mapping data structures were proposed for linking two metamodels instead of merging them or selecting one metamodel as a main one and extending it with elements from other one [31]. The semi-automatic extraction of business vocabularies from business process models was proposed in [32], but it only deals with vocabulary and does not include business rules.

Generating natural language texts from BPMN business process models was presented in [10]. The reverse approach of business process models generation from natural language texts was presented in [8]. Both methods [10], [8] use complex linguistic processing techniques and do not keep links between two models.

In order to get correct SBVR business vocabulary and business rules BPMN2 elements in BPMN2 business process model should follow strict naming rules [5], as BPMN2 has a large set of different events, these naming rules should be adapted individually according to BPMN2 event semantics. BPMN2 events is a larger subset in BPMN2, they represent different situations that might occur during the process flow. Therefore, these different event types should be processed differently during business vocabulary and rules creation as they have different semantic meanings.

The analysis leads to the conclusion that there is a need to create mappings between elements of SBVR and BPMN2 metamodels; it should not require the modification of SBVR and BPMN2 metamodels; it should provide BPMN2 strict element naming patterns for different BPMN2 element types in order to create semantically correct vocabulary as possible, also knowing that usage of a good business process modelling practice helps to simplify complex decisions and to reduce business process models.

When defining the transformations from BPMN2 to SBVR different BPMN2 naming patterns were used for different element types (activities, events, etc.). Also different naming patters were defined for BPMN2 events only in order to improve created transformation [33]. 
Improving BPMN2 Business Process Model to SBVR Business Vocabulary and Business Rules Transformation with BPMN2 Event Naming Patterns

\section{BPMN2 Event Types}

An event is something that "happens" during the course of a process and affects the flow of the process and usually has an impact and in general requires or allows for a specific reaction. The term "event" is general and covers situations such as the start of an activity, the end of an activity, the change of a state of the document, a message that arrives or leaves, etc.

BPMN2 has a huge set of events that differ in a purpose of the usage depending on the situation, which is expressed via BPMN2 business process models. BPMN2 has five event types: start events (start the process flow), intermediate catch events (wait for the event to be initialized to continue the process), intermediate throw events (send the message during the process flow), boundary events (represent how the business process responds to an exception) and end events (end the process flow). This grouping is based on how BPMN2 events are grouped in MagicDraw Case tool. All event types can have their own event types as can be seen from Fig. 1 .

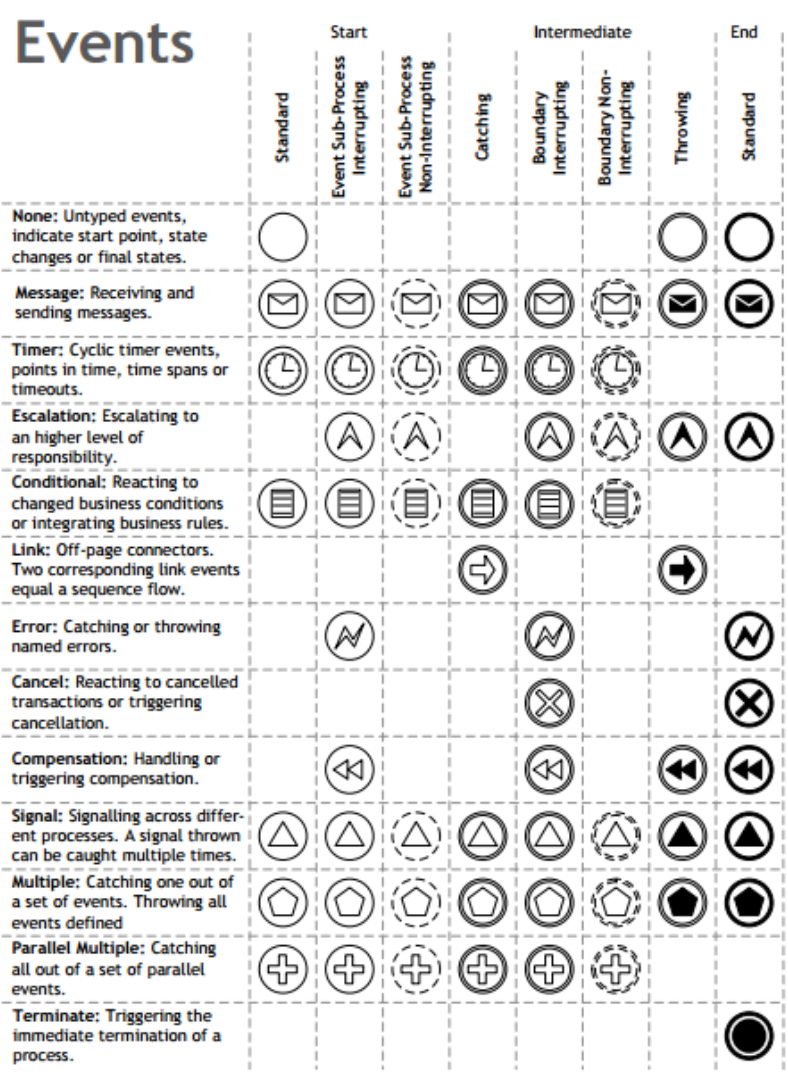

Figure 1. BPMN2 events [2]

Each event type is used in a different situation in a BPMN2 business process model. The large variety of BPMN2 events enable the possibility to express business process in a more detailed manner.

\section{Classification of BPMN2 Events by Names}

This section of the paper presents the classification of BPMN2 event types according to the naming formats. To avoid linguistic processing, we formulated naming rules [5] for BPMN elements. This section presents detailed naming rules for BPMN2 events. BPMN events naming patterns and restrictions are presented with the running example.

\subsection{BPMN2 Events Naming Rules and Patterns for Representing in SBVR}

BPMN events are classified into two groups (Table 1) according to what kind of naming formats BPMN2 events should have. These groups indicate how BPMN2 events that were assigned to one of the described groups are processed during the transformation from BPMN2 business process model to SBVR business vocabulary and business rules.

Table 1. Classification of BPMN2 event types

\begin{tabular}{cc}
\hline Color & Description \\
\hline & $\begin{array}{c}\text { Event name by the pattern } \\
\text { Event name, which is processed as a simple text } \\
\text { (free form). }\end{array}$ \\
\hline
\end{tabular}

All BPMN2 events are assigned to the appropriate group (Table 2) that shows what kind of name the event should have. Assignment depends on whether the event has an impact on business process or not. NonInterrupting and Interrupting BPMN2 event types are not distinguished separately as their names are processed in the same way.

Names of BPMN2 Link, Timer, Multiple and Parallel Multiple events should be formed following by certain restrictions. This ensures correct transformation from BPMN2 business process model to SBVR business vocabulary and business rules. Three types of patterns were identified and described using EBNF (Extended Backus-Naur Form) notation to represent how names of BPMN2 events should be formed in BPMN2 business process models.

1st pattern. This pattern is used for all BPMN2 events except for Timer, Multiple, Parallel Multiple and Link events.

first_name $=$ noun phrase, verb phrase for event, eg.: order is_received, when:

noun phrase $=[\{$ adjective $\}]$ noun [\{preposition $\}]$ [\{adjective\}] [\{preposition\}] [\{noun\}]

(e.g..: quick order of customer, department of information systems, tea from green fields)

verb phrase for event = "is "| "are "| "has "| "have", verb phase in past tense (e.g... is accepted)

2nd pattern. This pattern is used for BPMN Timer events. There are three types of BPMN2 Timer events: Time Duration, Time Cycle and Time Date. All these types should have certain verbs at the end of the name in order to correctly identify what kind of BPMN2 Timer event was used. 
Table 2. BPMN2 events and their assignment to the group

\begin{tabular}{lccccc}
\hline \multicolumn{1}{c}{ Event } & Start & $\begin{array}{c}\text { Intermediate } \\
\text { Catch }\end{array}$ & $\begin{array}{c}\text { Intermediate } \\
\text { Throw }\end{array}$ & Boundary & End \\
\hline None & $\checkmark$ & $\checkmark$ & & & $\checkmark$ \\
Message & $\checkmark$ & $\checkmark$ & $\checkmark$ & $\checkmark$ & $\checkmark$ \\
Timer & $\checkmark$ & & $\checkmark$ & \\
Error & $\checkmark$ & & $\checkmark$ & $\checkmark$ \\
Escalation & $\checkmark$ & $\checkmark$ & $\checkmark$ & $\checkmark$ \\
Cancel & & & $\checkmark$ & $\checkmark$ \\
Compensation & $\checkmark$ & $\checkmark$ & $\checkmark$ & \\
Conditional & $\checkmark$ & & & \\
Link & & & $\checkmark$ & $\checkmark$ \\
Signal & $\checkmark$ & $\checkmark$ & & $\checkmark$ \\
Terminate & & $\checkmark$ & $\checkmark$ & $\checkmark$ \\
Multiple & $\checkmark$ & $\checkmark$ & $\checkmark$ & \\
Parallel Multiple & $\checkmark$ & & & \\
\hline
\end{tabular}

\section{Time Duration:}

second_name $=$ noun phrase, verb phrase for timer time duration event, when

verb phrase for timer time duration event = "is "| "are "| "has "| "have", ,, passed" (e.g... week has_passed)

\section{Time Cycle:}

second_name $=$ noun phrase, verb phrase for timer time cycle event, when

verb phrase for timer time cycle event = "is "| "are"|"has"|"have", ,,reoccured" (e.g... monday has_reoccured)

\section{Time Date:}

second_name $=$ noun phrase, verb phrase for timer time date event, when

verb phrase for timer time date event = "is "| "are"|"has"|"have", ,_occured" (e.g... 7 a.m. has_occured)

3rd pattern. This pattern is used for BPMN2 Multiple and Parallel Multiple events. Pattern is based on 1st pattern joined with conjunctions "and" or "or".

third_name = first_name, "and"| "or", first_name, \{"and"|"or", first_name\}

Simple text. BPMN2 provides an option to use Link events to divide one large BPMN2 business process model into smaller parts. Link events that specify a break point of a process must have matching names. As BPMN2 Link events have no meaning to the flow of a process therefore transformation algorithm combines process into one and BPMN2 Link events are not included in the business vocabulary.

Examples of names of BPMN2 elements followed by defined patterns are presented in Table 3.
Three concept types can be formed from BPMN2 event depending on transformable BPMN2 event type.

Fig. 2 presents all formed SBVR vocabulary elements (in containment tree) from BPMN2 Message event "payment is received": general concepts "payment", "received" and "receive payment"; verb concept "payment has_state received".

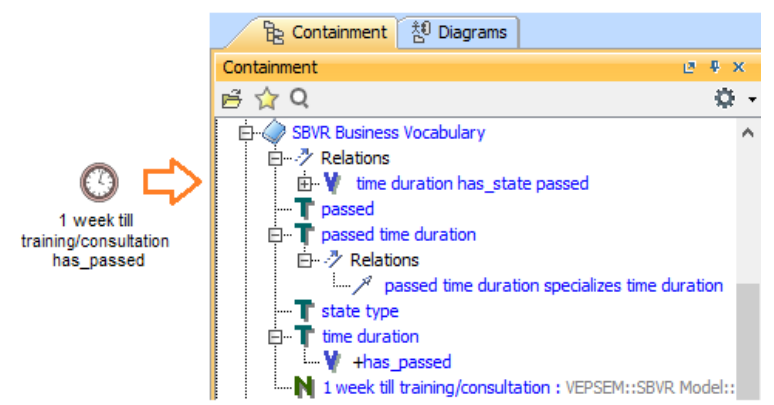

Figure 2. Transformation result from BPMN2 Timer event

Fig. 3 presents SBVR elements from BPMN2 Timer event "1 week till training/consultation has passed": individual concept "1 week till training/consultation"; general concepts "passed" and "passed time duration"; verb concept "time duration has_state passed".

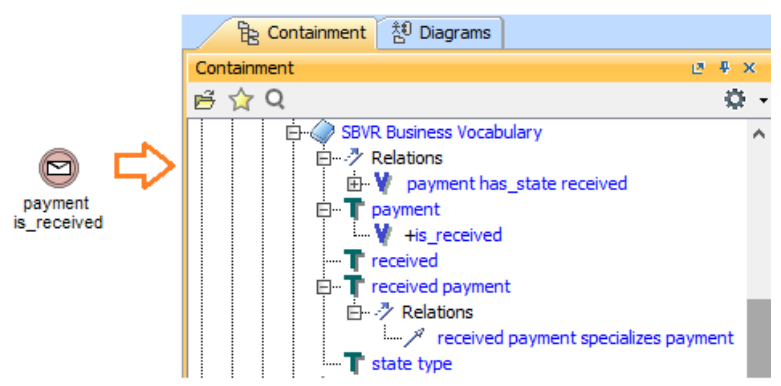

Figure 3. Transformation result from BPMN2 Message event 
Improving BPMN2 Business Process Model to SBVR Business Vocabulary and Business Rules Transformation with BPMN2 Event Naming Patterns

Table 3. Names of BPMN2 events followed by defined patterns

\begin{tabular}{|c|c|c|c|c|c|}
\hline Event & Start & $\begin{array}{l}\text { Intermediate } \\
\text { Catch }\end{array}$ & $\begin{array}{l}\text { Intermediate } \\
\text { Throw }\end{array}$ & Boundary & End \\
\hline None & rent car is_started & rent car is_started & & & $\begin{array}{l}\text { rent car } \\
\text { is_finished }\end{array}$ \\
\hline Message & $\begin{array}{l}\text { rental contract } \\
\text { is_received }\end{array}$ & $\begin{array}{l}\text { rental contract } \\
\text { is_received }\end{array}$ & $\begin{array}{l}\text { rental contract } \\
\text { is_sent }\end{array}$ & $\begin{array}{l}\text { error message } \\
\text { is_sent }\end{array}$ & $\begin{array}{l}\text { rental contract } \\
\text { is_sent }\end{array}$ \\
\hline $\begin{array}{l}\text { Timer } \\
\text { (moment, } \\
\text { interval, cycle) }\end{array}$ & $\begin{array}{l}10 \text { a.m. } \\
\text { has_occured }\end{array}$ & $\begin{array}{l}10 \text { business days } \\
\text { have_passed }\end{array}$ & & $\begin{array}{l}\text { week } \\
\text { has_reoccured }\end{array}$ & \\
\hline Error & order is_missing & & & $\begin{array}{l}\text { order item } \\
\text { is_missing }\end{array}$ & $\begin{array}{l}\text { customer email } \\
\text { is_ivalid }\end{array}$ \\
\hline Escalation & offer is_proposed & & offer is_checked & offer is_rejected & offer is_confirmed \\
\hline Cancel & & & & order is_cancelled & offer is_cancelled \\
\hline Compensation & $\begin{array}{l}\text { booking } \\
\text { is_compensated }\end{array}$ & $\begin{array}{l}\text { booking } \\
\text { is_compensated }\end{array}$ & $\begin{array}{l}\text { booking } \\
\text { is_compensated }\end{array}$ & $\begin{array}{l}\text { booking } \\
\text { is_compensated }\end{array}$ & $\begin{array}{l}\text { booking } \\
\text { is_compensated }\end{array}$ \\
\hline Conditional & order is_packed & $\begin{array}{l}\text { user information } \\
\text { is_correct }\end{array}$ & & $\begin{array}{l}\text { order item } \\
\text { is_broken }\end{array}$ & \\
\hline Link & & part1 & part1 & & \\
\hline Signal & account is_created & order is_rejected & $\begin{array}{l}\text { order item } \\
\text { is_shipped }\end{array}$ & offer is_rejected & $\begin{array}{l}\text { order } \\
\text { is_confirmed }\end{array}$ \\
\hline Terminate & & & & & order is_cancelled \\
\hline Multiple & $\begin{array}{l}\text { order is_sent or } \\
\text { order is_taken }\end{array}$ & $\begin{array}{l}\text { order } \\
\text { is_confirmed or } \\
\text { order is_repeated }\end{array}$ & $\begin{array}{l}\text { order } \\
\text { is_confirmed or } \\
\text { order is_repeated }\end{array}$ & $\begin{array}{l}\text { order item } \\
\text { is_broken or order } \\
\text { item is_wrong }\end{array}$ & $\begin{array}{l}\text { order is_canceled } \\
\text { or order } \\
\text { is_shipped }\end{array}$ \\
\hline $\begin{array}{l}\text { Parallel } \\
\text { Multiple }\end{array}$ & $\begin{array}{l}\text { credit card } \\
\text { is_valid and } \\
\text { driving licence } \\
\text { is_valid }\end{array}$ & $\begin{array}{l}\text { user information } \\
\text { is_checked and } \\
\text { offer is_prepared }\end{array}$ & & $\begin{array}{l}\text { order discount } \\
\text { is_applied and } \\
\text { order is_paid }\end{array}$ & \\
\hline
\end{tabular}

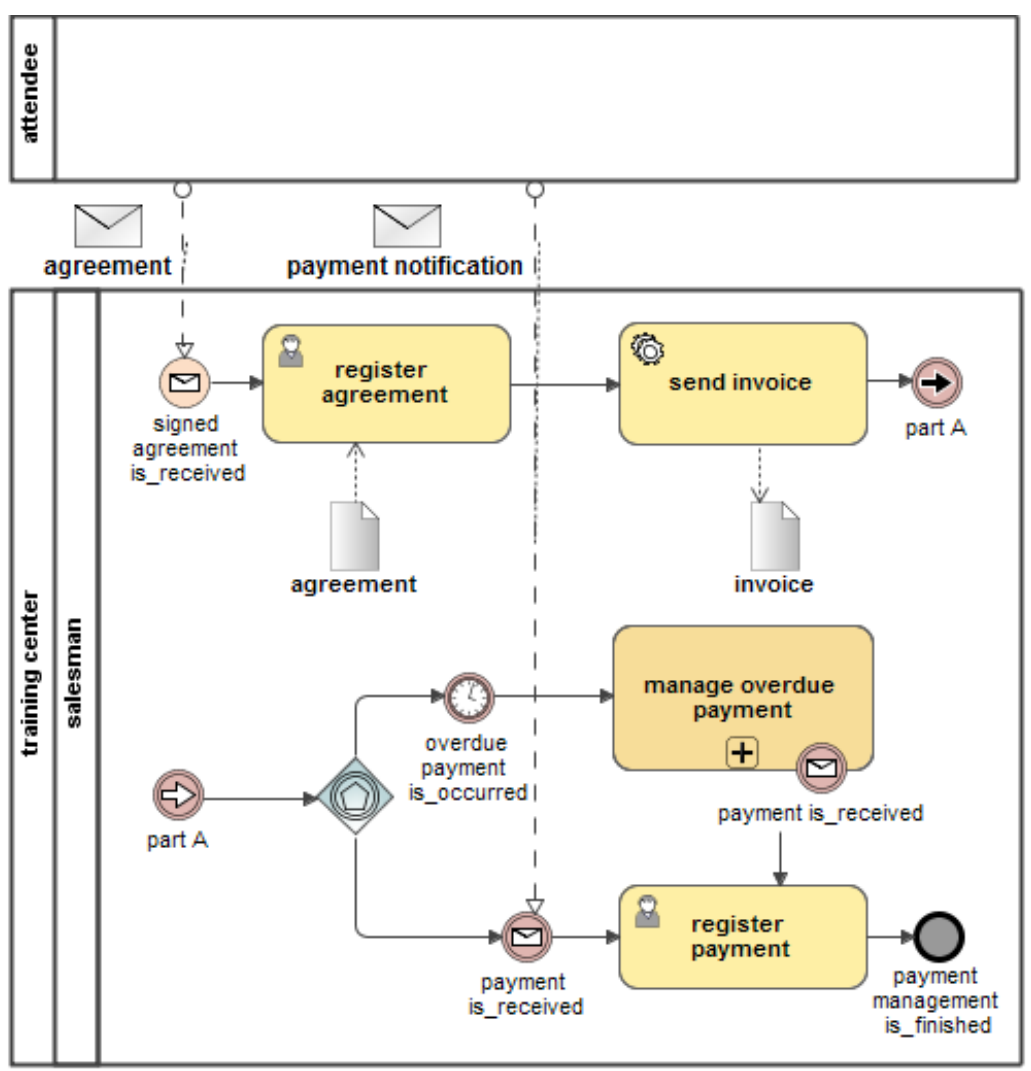

Figure 4. BPMN2 process "manage payment" 


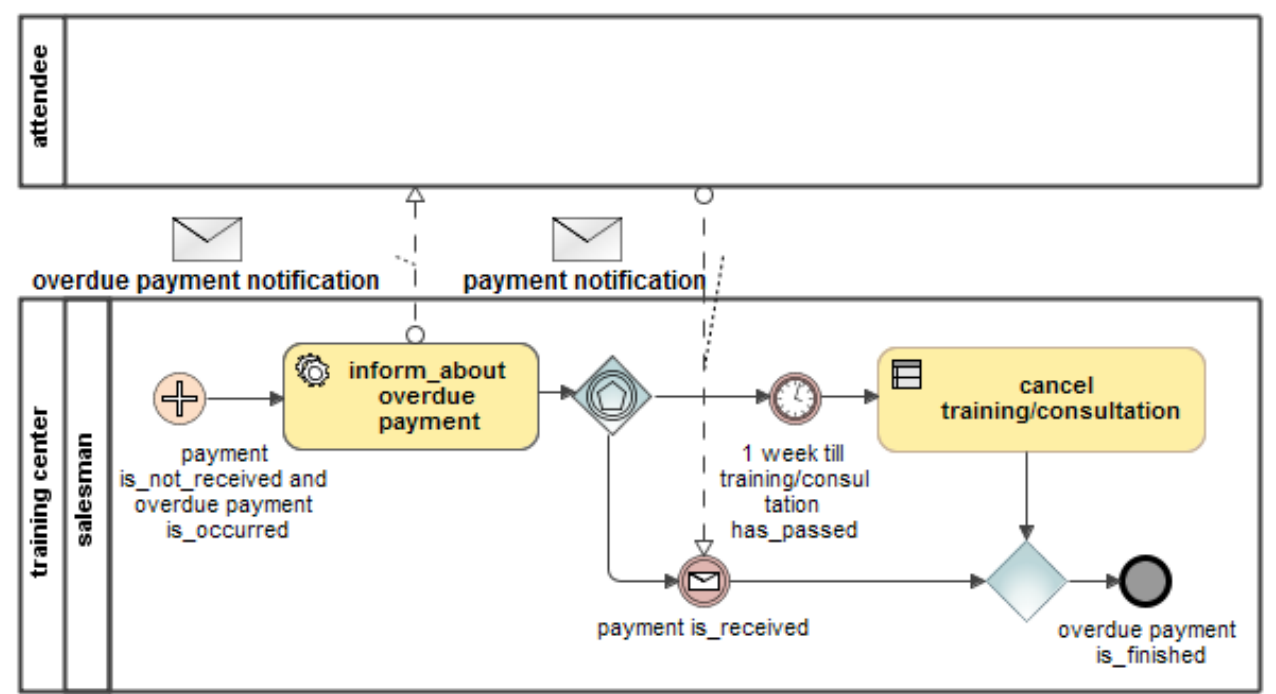

Figure 5. BPMN2 subprocess "manage overdue payment"

Table 4. SBVR general concepts

\begin{tabular}{|c|c|c|c|}
\hline No. & SBVR general concept & No. & SBVR general concept \\
\hline 1. & agreement & 14. & $\begin{array}{l}\text { passed time duration ( } 2) \\
\text { General concept: time duration }\end{array}$ \\
\hline 2. & attendee & 15. & payment (1) (3) \\
\hline 3. & finished (1) & 16. & payment management (1) \\
\hline 4. & $\begin{array}{l}\text { finished overdue payment (1) } \\
\text { General concept: overdue payment } \\
\text { Necessity: is_included_in Overdue payment by state type }\end{array}$ & 17. & payment notification \\
\hline 5. & $\begin{array}{l}\text { finished payment management (1) } \\
\text { General concept: payment management }\end{array}$ & 18. & received (1) \\
\hline 6. & invoice & 19. & $\begin{array}{l}\text { received payment (1) } \\
\text { General concept: payment } \\
\text { Necessity: is_included_in Payment by state type }\end{array}$ \\
\hline 7. & not_received (3) & 20. & $\begin{array}{l}\text { received signed agreement } \\
\text { General concept: signed agreement }\end{array}$ \\
\hline 8. & $\begin{array}{l}\text { not_received payment (3) } \\
\text { General concept: payment } \\
\text { Necessity: is_included_in Payment by state type }\end{array}$ & 21. & salesman \\
\hline 9. & occurred (2) (3) & 22. & signed agreement (1) \\
\hline 10. & $\begin{array}{l}\text { occurred overdue payment (2) (3) } \\
\text { General concept: overdue payment } \\
\text { Necessity: is_included_in Overdue payment by state type }\end{array}$ & 23. & state type \\
\hline 11. & overdue payment (1) (2) (3) & 24. & time duration \\
\hline 12. & overdue payment notification & 25. & training/consultation \\
\hline 13. & passed (2) & 26. & training center \\
\hline
\end{tabular}

General concept "state type" is formed automatically if transformation algorithm finds at least one state change which occures with verb concept that has verb „has_state“. Thus general concepts that go after „has_state" has its concept type ("state type").

All SBVR business rules are formed using BPMN2 event names. A fragment of rules was presented in [5].

\subsection{Example of BPMN Business Process to SBVR Business Vocabulary and Business Rules}

In order to demonstrate BPMN2 events transformation to SBVR business vocabulary, simple example is presented in this section. Fig. 4 presents the process of payment management "manage payment". Fig. 5 presents subprocess "manage overdue payment" from the process "manage payment". 
Improving BPMN2 Business Process Model to SBVR Business Vocabulary and Business Rules Transformation with BPMN2 Event Naming Patterns

Transformation results are presented in Tables 4-7. These tables include all the SBVR business vocabulary concepts and business rules that were formed during transformation. SBVR concepts that were formed from events are marked with numbers in brackets as follows: (1) - from the 1st pattern, (2) - from the 2nd pattern (BPMN Timer events), (3) - from the 3rd pattern (BPMN Multiple and BPMN Parallel Multiple events) and (4) - as a simple text (BPMN2 Link events). Rule in Table 7 marked with $\left(^{*}\right)$ shows SBVR rule formulation with BPMN Boundary events, although event name is formed using the 1 st pattern. Some SBVR concepts have more than one marker, this means that SBVR concept could be formed from several types of BPMN2 events depending on which event will be processed first (as SBVR concepts are created just once). Table 4 presents SBVR general concepts.

Table 5 presents SBVR individual concepts. Last two individual concepts are formed for implementation of the categorization scheme.

Table 5. SBVR individual concepts

\begin{tabular}{ll}
\hline No. & SBVR individual concept \\
\hline 1. & 1 week till training/consultation (2) \\
& General concept: time duration \\
2. & Overdue payment by state type (1) (2) (3) \\
& Necessity: categorization schema for general \\
concept overdue payment that subdivides overdue & payment by state type \\
Payment by state type (1) (3) \\
Necessity: categorization schema for general \\
concept payment that subdivides payment by state \\
type
\end{tabular}

Table 6 presents SBVR verb concepts.

Table 6. SBVR verb concepts

\begin{tabular}{ll}
\hline No. & SBVR verb concept \\
\hline 1. & overdue payment has_state finished (1) \\
2. & overdue payment has_state occurred (2) (3) \\
3. & payment has_state not_received (3) \\
4. & payment has_state received (1) \\
5. & payment management has_state finished (1) \\
6. & salesman cancel training/consultation \\
7. & salesman inform_about overdue payment \\
8. & salesman manage overdue payment \\
9. & salesman register agreement \\
10. & salesman register payment \\
11. & salesman send invoice \\
12. & signed agreement has_state received (1) \\
13. time duration has_state passed (2) \\
14. training center include salesman
\end{tabular}

Table 7 presents SBVR operative business rules. SBVR business rules are formed in the context of relationships between BPMN2 elements, therefore not all rules are marked. Marker was used to distinguish certain rules from all. Other SBVR rules are formed by transformation rules [5] using names of BPMN2 events.

Table 7. SBVR operative business rules

\begin{tabular}{ll}
\hline No. & SBVR business rule \\
\hline 1. & $\begin{array}{l}\text { It is obligatory that attendee receive overdue } \\
\text { payment notification after salesman send overdue } \\
\text { payment notification }\end{array}$ \\
2. & $\begin{array}{l}\text { It is obligatory that overdue payment is_occured } \\
\text { or payment is_received after salesman send } \\
\text { invoice (4) }\end{array}$ \\
3. It is obligatory that overdue payment is_finished \\
after payment is_received or salesman cancel \\
training/consultation
\end{tabular}

4. It is obligatory that payment is_received or 1 week till training/consultation has_passed after salesman inform_about overdue payment

5. It is obligatory that payment management is_finished after salesman register payment

6. It is obligatory that payment is_received after salesman receive payment notification

7. It is obligatory that salesman register payment if payment is_received while salesman manage overdue payment $(*)$

8. It is obligatory that salesman manage overdue payment after overdue payment is_occured

9. It is obligatory that salesman cancel training/consultation after 1 week till training/consultation has_passed

10. It is obligatory that salesman register agreement after signed agreement is_received

11. It is obligatory that salesman inform_about overdue payment after payment is_not_received and overdue payment is_occured

12. It is obligatory that salesman send invoice after salesman register agreement

13. It is obligatory that salesman send overdue payment notification when salesman inform_about overdue payment

14. It is obligatory that salesman register payment after payment is_received

15. It is obligatory that salesman receive agreement after attendee send agreement

16. It is obligatory that salesman receive payment notification after attendee send payment notification

17. It is obligatory that signed agreement is_received after salesman receive agreement

BPMN2 business process model to SBVR business vocabulary and business rules transformation algorithm goes through all the elements and their combinations in a process model and forms general concepts, verb concepts, individual concepts, business rules from BPMN2 element names using transformation rules [5]. These rules show how BPMN2 element names are used to form required SBVR concepts. For this reason, there is important to follow the restrictions (patterns) for BPMN2 element names that were defined in [5] and 
Table 7. Experimental results of transforming original and adapted Magic Library process models

\begin{tabular}{ccccccc}
\hline Magic Library Domain & $|\mathbf{R E} \cap \mathbf{A E}|$ & $|\mathbf{A E}|$ & $|\mathbf{R E}|$ & $\mathbf{P}$ & $\mathbf{R}$ & $\mathbf{F}$ \\
\hline Original model & 26 & 61 & 53 & 0,43 & 0,49 & 0,46 \\
Adapted model & 53 & 53 & 53 & 1 & 1 & 1 \\
\hline
\end{tabular}

additionally defined patterns for BPMN2 events presented in this article. BPMN2 business process model transformation to SBVR business vocabulary and business rules was implemented using QVT transformation language [21]. This transformation capability along with the transformation to SBVR business rules were included in MagicDraw UML Case tool using SBVR Profile and was presented in [7]. Therefore, SBVR concepts can be presented as a diagram using graphical elements. SBVR business rules are presented as simple text in a separate table.

\section{Experimental Evaluation}

An experimental evaluation was applied to Magic Library domain (original BPMN2 model was taken from MagicDraw CASE tool example library) by transforming BPMN2 process model events (with associated elements) to SBVR business process concepts and rules. To compare how the requirements to BPMN2 event names affect transformation correctness, transformations were accomplished with Magic Library domain twice: with the original model (from example library) and with the model that was adapted to requirements (using naming patterns). Transformation results (Table 7) were evaluated using the following criteria:

$$
\begin{aligned}
& P=\frac{|R E \cap A E|}{|A E|} \\
& R=\frac{|R E \cap A E|}{|R E|} \\
& F=2 \times \frac{P \times R}{P+R}
\end{aligned}
$$

Here $\mathrm{P}$ means precision, $\mathrm{R}$ - recall; $\mathrm{RE}$ - a set of transformable BPMN2 events; AE - a set of actually

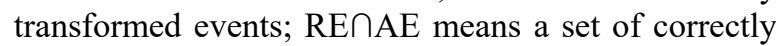
transformed events; F - F-measure (a balanced F-score). Transformations include events and associated elements that are necessary to compose SBVR rules.

The experimental evaluation has shown that process model which is created using naming patterns ensure much better transformation results (Adapted model in Table 7) compared with the original process. Therefore, modelers have to put more efforts into modelling that all elements would have unified format names (as events using proposed patterns) in order to get correct SBVR business vocabulary and business rules. All naming requirements for BPMN2 elements can be found in [5].

\section{Conclusions and Future Works}

The paper presents BPMN2 events and their representation in SBVR in order to allow the BPMN business process models transformation to SBVR business vocabulary and rules. BPMN2 element set is larger than SBVR, this is most visible while examining BPMN2 events. In order to get full and comprehensive BPMN2 vocabulary, BPMN2 events should be processed differently. This paper presents SBVR business vocabulary formation from BPMN2 business process models. The presented example demonstrates this capability.

BPMN2 business process models transformation to SBVR business vocabulary and rules is implemented in MagicDraw UML Case tool. The methodology for integrated modelling of business processes and business rules in a user-friendly and clear way is presented in conjunction with this VEPSEM plugin in the mentioned tool.

Experimental evaluation has shown that it is vital to apply requirements to BPMN2 elements in order to get SBVR business vocabulary and business rules that make sense. Otherwise transformation result from freely created process models is significantly worse.

Our future work is devoted to BPMN2 business process models transformation to SBVR business process vocabulary and rules in order to allow reverse transformation with the minimum loss of information.

\section{Acknowledgments}

The work is supported by the project VP1-3.1ŠMM-10-V-02-008, „Integration of Business Processes and Business Rules on the Basis of Business Semantics" (2013-2015), which is funded by the European Social Fund (ESF).

\section{References}

[1] A. Agrawal. Semantics of Business Process Vocabulary and Process Rules. In ISEC '11 proceedings of the 4th India Software Engineering Conference, 2011, pp. 61-68.

[2] BPMN 2.0 Poster. http://www.bpmb.de/poster, 2011.

[3] J. A. Bubenkbo Jr. Challenges in requirements engineering, In Proceedings of the Second IEEE Symposium on Requirements Engineering, IEEE Computer Society, 1995, pp. 160-162.

[4] J. Recker. Opportunities and constraints: the current struggle with BPMN. Business Process Management Journal, 2010, Vol. 16, No. 1. pp. 181-201. 
Improving BPMN2 Business Process Model to SBVR Business Vocabulary and Business Rules Transformation with BPMN2 Event Naming Patterns

[5] E. Mickeviciute, L. Nemuraite, R. Butleris. Applying SBVR Business Rules Vocabulary and Business Rules for Creating BPMN Process Models. In W. Abramowicz and A. Kokkinaki (Eds.): BIS 2014 Workshops, LNBIP, Vol. 183, Switzerland Springer International Publishing, pp.1-12.

[6] E. Mickeviciute, R. Butleris. Towards the Combination of BPMN Process Models with SBVR Business Vocabularies and Rules. In Information and software technologies: 19th International Conference, ICIST 2013, Kaunas, Lithuania, October 10-11, Springer, 2013. CCIS, Vol. 403, pp. 114-121. Springer Berlin Heidelberg.

[7] E. Mickeviciute, S. Pavalkis, L. Nemuraite, R. Butleris. Using SBVR Profile for Integrating Business Vocabulary with BPMN Process Models. In International journal of advances in computer science $\&$ its applications, 2014. New York: IRED. ISSN 22503765. 2014, Vol. 4, No. 3, pp. 108-113.

[8] F. Friedrich, J. Mendling, F. Puhlmann. Process Model Generation from Natural Language Text. In Advanced Information Systems Engineering, LNCS, 2011, Vol. 6741, pp. 482-496. Springer Berlin Heidelberg.

[9] D. Greer, G. Ruhe. Software release planning: an evolutionary and iterative approach, Information and Software Technology, Vol. 46, No. 4, 2004, pp. 243253.

[10] H. Leopold, J. Mendling, A. Polyvyanyy. Generating Natural Language Texts from Business Process Models. In Advanced Information Systems Engineering, LNCS, 2012, Vol. 7328, pp. 64-79. Springer Berlin Heidelberg.

[11] J. Hohwiller, D. Schlegel, G. Grieser, Y. Hoekstra. Integration of BPM and BRM. In Dijkman, R. Hofstetter, J., Koehler, J. (eds.), LNBIP, 2011, Vol. 95 , pp. 136-141. Springer, Heidelberg.

[12] J. Koehler. The Process-Rule Continuum - How can the BPMN and SBVR Standarts inteplay? Lucerne University of Applied Sciences and Arts, Swicerland, 2010.

[13] J. Sinur. The art and science of rules vs. Process flows. In Research Report G00166408, Gartner, 2009.

[14] KnowGravity. KnowEnterprise. Version 1.7 http://www.knowgravity. Com, 2012.

[15] L. Ceponiene, L. Nemuraite, G. Vedrickas. Separation of event and constraint rules in UML\&OCL models of service oriented information systems. Information Technology and Control, 2009, Vol. 38 , No. 1, pp. 29-37.

[16] L. Nemuraite, T. Skersys, A. Sukys, E. Sinkevicius, L. Ablonskis. VETIS tool for editing and transforming SBVR business vocabularies and business rules into UML\&OCL models. In Proceedings of the 16th International Conference on Information and Software Technologies, IT 2010, Kaunas, Lithuania, April 21-23, pp. 377-384.

[17] M. Milanovic, D. Gaševic, L. Rocha. Modeling Flexible Business Process with Business Rule Patterns. In 2011 15th IEEE International Enterprise Distributed Object Computing Conference.

[18] M. Schacher. Business Rules from an SBVR and
xUML Perspective (Parts 1-3). Business Rules Journal, 2006, Vol. 7, No. 6-8.

[19] M. Zur Muehlen, M. Indulska. Modeling Languages for Business Processes and Business Rules: A representational Analysis. Information Systems, 2010, Vol. 35, No. 4, pp. 379-390.

[20] OMG. Business Process Model and Notation (BPMN). Version 2.0.1 OMG Document Number: formal/201309-02.

[21] OMG. Meta Object Facility (MOF) 2.0 Query/View/Transformation Specification. Version 1.1, January 2011. OMG Document Number: formal/201101-01.

[22] OMG. Semantics of Business Vocabulary and Business Rules (SBVR) specification. Version 1.0. OMG Document Number: formal/2008-01-02.

[23] OMG. Semantics of Business Vocabulary and Business Rules (SBVR) specification. Version.1.1, OMG Document Number: formal/2013-09-04.

[24] P. Musham, S. Singh, R. Tv P. Bahal. Visual SBVR. In Digital Information Management, ICDIM 2008, pp. 676-683.

[25] R. Cheng, S. Sadiq, M. Indulska. Framework for Business Process and Rule Integration: A Case of BPMN and SBVR. In Business Information Systems, LNBIP, 2011, Vol. 87, pp. 13-24.

[26] R. G. Ross. The business Rule Book. Business Rule Solutions, Houston, 2nd ed, 1997.

[27] S. Goedertier, J. Vanthienen. Declarative Process Modeling with Business Vocabulary and Business Rules. In OTM 2007 Ws, Part I, LNCS, 2007, Vol.4805, pp.603-612, Springer-Verlag Berlin Heidelberg.

[28] S. Malik, I. S. Bajwa. Back to Origin: Transformation of Business Process Models to Business Rules. In Business Process Management Workshops, LNBIP, 2013, Vol. 132, pp.611-622. Springer-Verlag Berlin Heidelberg.

[29] S. Malik, I. S. Bajwa. A Rule Based Approach for Business Rule Generation from Business Process Model. In Business Process Management Workshops, Rules on the Web: Research and Applications, LNCS, 2012, Vol. 7438, pp. 92-99. Springer-Verlag Berlin Heidelberg.

[30] T. Graml, R. Bracht, M. Spies. Patterns of Business Rules to Enable Agile Business Processes. In 11th IEEE International Enterprise Distributed Object Computing Conference, 2008, Vol. 2, No. 4, pp. 385-402.

[31] T. Skersys, L. Tutkute, R. Butleris, R. Butkiene. Extending BPMN Business Process Model with SBVR Business Vocabulary and Rules. Information Technology and Control, 2012, Vol. 41, No. 4, 356367.

[32] T. Skersys, R. Butleris, K. Kapocius, T. Vileiniskis. An Approach for Extracting Business Vocabularies from Business Process Models. Information Technology and Control, 2013, Vol. 42, No. 2, 178-190.

[33] VEPSEM. Integration of Business Processes and Business Rules on the Base of Business Semantics (VP131V008F). Project Report, VP1-3.1-ŠMM-10-V02-008, Kaunas University of Technology, 2015.

Received May 2016. 